\title{
Research skills of Queensland Health podiatrists: how do they rate and are they improving?
}

\author{
Peter A Lazzarini ${ }^{1,2,3^{*}}$, Julia Geraghty ${ }^{3}$, Ewan M Kinnear ${ }^{2}$, Mark Butterworth ${ }^{4}$, Donna Ward ${ }^{5}$ \\ From Australasian Podiatry Council Conference 2013 \\ Sydney, Australia. 2-5 June 2013
}

\section{Background}

For health professions to evolve in a highly evidencebased world it seems imperative for clinicians to build their research skills. This observational paper aims to report the research skill levels of statewide public-sector podiatrists at two different time points twelve-months apart.

\section{Methods}

The Research Capacity \& Culture (RCC) survey was distributed to all Queensland Health podiatrists in January $2011(\mathrm{n}=58)$ and January $2012(\mathrm{n}=60)$. The RCC is a validated tool designed to measure indicators of research skill in health professionals. Participants rate skill levels against each individual, team and organisation statement on a 10 -point scale ( $1=$ lowest, $10=$ highest). Chi-squared and Mann Whitney $U$ tests were used to determine any differences between survey samples.

\section{Results}

Thirty-seven (64\%) podiatrists responded to the 2011 survey and 33 (55\%) the 2012 survey. The 2011 survey respondents reported low skill levels $($ Median $<4$ ) on most individual research aspects. However, most reported their organisations' skills to perform and support research at higher levels (Median>6). The 2012 survey respondents reported significantly higher skill levels compared to the 2011 survey in individuals' ability to secure research funding, submit ethics applications and provide research advice $(\mathrm{p}<0.05)$.

\section{Conclusions}

This study reports the research skill levels of the largest podiatry populations to date. The 2011 findings indicated

${ }^{1}$ Allied Health Research Collaborative, Metro North Hospital \& Health Service, Queensland Health, Brisbane, Queensland, 4032, Australia

Full list of author information is available at the end of the article that podiatrists have similarly low research skill levels to those reported in the generic allied health literature. The 2012 findings suggest podiatrists perceived higher skills and support to initiate research than in 2011. This improvement coincided with podiatry research capacity building strategies.

\section{Author details}

${ }^{1}$ Allied Health Research Collaborative, Metro North Hospital \& Health Service, Queensland Health, Brisbane, Queensland, 4032, Australia. ${ }^{2}$ Department of Podiatry, Metro North Hospital \& Health Service, Queensland Health, Brisbane, Queensland, 4032, Australia. ${ }^{3}$ School of Clinical Sciences, Queensland University of Technology, Brisbane, Queensland, 4059, Australia. ${ }^{4}$ Department of Allied Health Services, Metro North Hospital \& Health Service, Queensland Health, Brisbane, Queensland, 4032, Australia. ${ }^{5}$ Department of Clinical Psychology \& Neuropsychology, The Prince Charles Hospital, Queensland Health, Brisbane, Queensland, 4032, Australia.

Published: 31 May 2013

doi:10.1186/1757-1146-6-S1-P9

Cite this article as: Lazzarini et al:: Research skills of Queensland Health podiatrists: how do they rate and are they improving? Journal of Foot and Ankle Research 2013 6(Suppl 1):P9.

Submit your next manuscript to BioMed Central and take full advantage of:

- Convenient online submission

- Thorough peer review

- No space constraints or color figure charges

- Immediate publication on acceptance

- Inclusion in PubMed, CAS, Scopus and Google Scholar

- Research which is freely available for redistribution 